\title{
1 educação de jovens e adultos em áreas de reforma agrária: desafios da formação de educadores do campo
}

Lourdes Helena da Silva

Universidade Federal de Viçosa

Vânia Aparecida Costa

Universidade do Estado de Minas Gerais

Walquíria Miranda Rosa

Universidade do Estado de Minas Gerais

\section{Introdução}

Em virtude dos altos índices de analfabetismo e baixos níveis de escolaridade presentes em nosso país, a educação de jovens e adultos tem se tornado objeto de políticas públicas dos governos federal, estaduais e municipais. A realidade do analfabetismo na sociedade brasileira é ainda mais alarmante quando deslocamos nosso olhar para o campo. Dados do Instituto Nacional de Colonização e Reforma Agrária (INCRA) revelam a existência de um universo de 6.567 .682 (32,7\%) jovens e adultos analfabetos no meio rural brasileiro. E, ainda, dados de pesquisa realizada pela organização não governamental Ação Educativa em convênio 
com o INCRA revelaram que $64 \%$ dos 323.429 assentados em áreas de reforma agrária são analfabetos funcionais (Andrade et al., 2004). Esses índices retratam, assim, a realidade educacional dos trabalhadores rurais que lutam pela reforma agrária e que não é diferente do quadro geral de exclusão social presente no campo brasileiro.

Dessa realidade socioeducativa emergem diversos projetos de alfabetização de jovens e adultos nas áreas de reforma agrária, implementados nacionalmente como resultantes de mobilização e conquista dos movimentos sociais e de uma articulação de várias instituições públicas na busca de contribuir na elaboração e implementação de projetos de uma educação do campo, contemplando ações educativas que visam ao direito da "Educação para todos" e à formação de cidadãos conscientes e participativos. O Programa Nacional de Educação na Reforma Agrária (PRONERA) representa uma dessas conquistas dos agricultores, especificamente vinculada ao Movimento dos Trabalhadores Rurais Sem Terra (MST) e ao movimento sindical da Confederação Nacional dos Trabalhadores na Agricultura (CONTAG).

Fruto do protagonismo desses movimentos, o PRONERA tem cumprido, nas duas últimas décadas, ${ }^{1}$ um papel importante no cenário educacional brasileiro, principalmente no âmbito da Educação de Jovens e Adultos (EJA). Buscando contribuir com a elevação da escolaridade - nos níveis fundamental, médio e superior - e com a formação continuada de educadores, entre outros propósitos o PRONERA tem sido um

O PRONERA tem atualmente 12 anos, portanto temos o final da década de 1990 e a primeira década do século XXI. dos espaços de construção da educação do campo, cujos princípios buscam a valorização da identidade do camponês e o seu reconhecimento como sujeito integrante da sociedade e portador de uma história e de uma cultura próprias.

A expressão educação do campo, mais que uma simples mudança de nomenclatura - rural para campo constituiu um dos traços marcantes da identidade de um movimento nacional construído com a mobilização da população do campo. Por meio de suas organizações e movimentos sociais, busca reagir ao processo de exclusão social, reivindicando novas políticas públicas que garantam não apenas o acesso à escola, mas o direito a uma educação no/do campo (Silva, 2008). É um movimento que, conforme destaca Caldart (2004), mais que o direito de a população ser educada no lugar onde vive, defende o direito a uma educação pensada desde o seu lugar e com a sua participação, vinculada à sua cultura e às suas necessidades humanas e sociais.

Em Minas Gerais, uma das ações do PRONERA, orientada pelos princípios e práticas da educação do campo, é o Projeto Educação, Campo e Consciência Cidadã, desenvolvido por meio de parceria entre a Universidade do Estado de Minas Gerais (UEMG), Universidade Federal de Viçosa (UFV), Faculdade de Filosofia e Letras de Diamantina (FAFIDIA), Federação dos Trabalhadores na Agricultura de Minas Gerais (FETAEMG), MST e o INCRA. Implantado desde 2001, seu objetivo é promover a formação de educadores/as e a alfabetização/ escolarização de jovens e adultos de assentamentos e acampamentos de reforma agrária nas diferentes regiões de Minas Gerais. 
As experiências acumuladas ao longo de oito anos de execução do Projeto Educação, Campo e Consciência Gidadã têm demandado pesquisas acadêmicas com o objetivo tanto de suprir a escassez de informações sistematizadas sobre tal projeto quanto o de avaliar as condições e os resultados das propostas pedagógicas implementadas, principalmente em termos do alcance de suas metas, das potencialidades e limites dos processos pedagógicos e das dinâmicas de parceria implementadas. Cabe ressaltar que não são muitas as pesquisas no Brasil que avaliam os impactos de programas de educação de jovens e adultos, tanto do ponto de vista das habilidades de leitura e escrita dos jovens e adultos inseridos em programas governamentais, quanto dos processos de formação de educadores e educadoras promovidos por esses programas. Essa lacuna teórica, segundo Ribeiro (2001), acarreta um limite na produção do conhecimento no campo da EJA e especialmente de análises de resultados das políticas públicas nessa área. "Nas últimas duas décadas, o tema da avaliação de rendimento e impactos de programas de educação de jovens e adultos esteve praticamente ausente das pesquisas acadêmicas, como demonstra o levantamento da produção da pós-graduação entre 1986 e 1998, coordenada por Haddad" (Ribeiro, 2001, p. 1).

Todavia, cabe destacar que em relação ao PRONERA foi desenvolvida uma avaliação externa, em pesquisa intitulada $A$ educação na reforma agrária em perspectiva: uma avaliação do Programa Nacional de Educação na Reforma Agrária (Andrade et al., 2004). Nessa pesquisa, foram encontrados resultados positivos do programa, além de reforçadas "as conclusões de estudos recentes sobre os impactos positivos dos assentamentos no meio rural no qual se instalam" (idem, p. 8). Em relação aos projetos de alfabetização de jovens e adultos, a pesquisa identificou que somente $61,76 \%$ dos educandos concluem o processo de alfabetização. Entre as inúmeras dificuldades relacionadas à desistência desses sujeitos, destacam-se: “a) quantidade de trabalho na roça e doméstico; b) alta incidência de deficiência visual; c) idade avançada; d) infraestrutura precária das salas; e) grande distância sala de aula/moradia" (idem, p. 10), além do estigma social que pesa sobre os analfabetos. Embora considerada significativa, essa pesquisa não atingiu o estado de Minas Gerais, tendo em vista que na Região Sudeste foi selecionado apenas o estado do Espírito Santo para composição do estudo.

Na especificidade do Projeto Educação, Campo e Consciência Cidadã, os dados dos relatórios do mesmo período da pesquisa revelam índices de frequência próximos da pesquisa nacional. Todavia, esses resultados têm nos desafiado a enfrentar algumas questões que podem ser assim resumidas: Quais os impactos do processo de formação dos educadores e educadoras envolvidos no projeto, no cotidiano de suas práticas pedagógicas na sala de aula? Que fatores têm favorecido e/ou dificultado o desenvolvimento, pelos educadores e educadoras, de uma prática educativa libertadora? Como se expressam, na trajetória sociopessoal dos educandos/ as assentados/as, os impactos das práticas educativas e do processo de alfabetização vivenciados? E, no conjunto da dinâmica educativa, como os diferentes parceiros avaliam os impactos e resultados do projeto executado? 
É nessa perspectiva que se inscreve o Programa de Estudos "Educação de jovens e adultos em áreas de reforma agrária em Minas Gerais: os processos educativos gestados no Projeto Educação, Campo e Consciência Cidadã", ${ }^{2}$ cujo objetivo geral foi analisar os impactos, avanços e limitações do processo de alfabetização de jovens e adultos, desenvolvidos pelo projeto citado. Especificamente, foram nossos propósitos de pesquisas:

a Em relação ao conjunto dos parceiros envolvidos - universidades, MST, FETAEMG e INCRA -, identificar suas avaliações sobre o projeto e analisar suas representações sociais sobre a dinâmica de gestão implementada.

b Em relação aos educadores/as, construir uma caracterização desses sujeitos e das práticas desenvolvidas no trabalho de alfabetização, de maneira que identifique, no processo de formação vivenciado por eles/as, os fatores explicativos da adoção de um determinado conceito de alfabetização e educação de jovens e adultos.

c Em relação aos educandos/ as, descrever a trajetória dos assentados/as envolvidos no projeto, de maneira que identifique tanto os impactos do

Programa de Estudos financiado pela Fundação de Amparo à Pesquisa do Estado de Minas Gerais (FAPEMIG), realizado no período de 2006 a 2009. Ver Silva et al., em Simpósio Nacional Investigação em Psicologia, 7., 2010, Braga/Portugal. Anais... Braga/ Portugal. processo de alfabetização em suas vidas socioprofissionais quanto analisar suas representações sociais sobre o projeto.

No presente trabalho, nosso propósito é apresentar análises e sistematizações construídas com base nos resultados do Programa de Estudos, especificamente das pesquisas realizadas respectivamente com educadores/ as e educandos/as, de maneira que evidenciem as conquistas, demandas e desafios colocados por estes/as sujeitos da EJA nos processos formativos do Projeto Educação, Campo e Consciência Cidadã.

Em termos de aportes teóricos utilizados, a noção de representação social (Moscovici, 1978) assumiu centralidade nas pesquisas que, por sua vez, foram exploradas em articulação com a noção de trajetórias (Bourdieu, 1994), contribuindo, assim, como esclarecedoras das condições do contexto social e cultural nos quais as representações sociais se constituem.

Em termos metodológicos, a relativa novidade do Projeto Educação, Campo e Consciência Cidadã deve-se à ausência de estudos e análises sobre essa experiência educativa, o que favoreceu um contexto de descoberta. Assim, a pesquisa qualitativa apresentou-se como a mais apropriada para sondar e apreender este "objeto novo" ao permitir, mais que medir a sua amplitude e confirmar sua universalidade, revelar suas singularidades. Nessa perspectiva, os procedimentos utilizados para a coleta de dados conjugaram a aplicação de questionários e a realização de entrevistas semiestruturadas. Enquanto a utilização do questionário 
teve como objetivo a caracterização socioprofissional dos entrevistados, a realização das entrevistas teve como objetivo identificar as representações sociais. Na escolha dos entrevistados, utilizamos a representatividade dos grupos investigados, usualmente designada como amostra intencional (Thiollent, 1986); na interpretação dos dados, utilizamos o método de análise de conteúdo, apoiando-nos nas proposições desenvolvidas por Bardin (1977).

\section{Projeto Educação, Campo e Consciência Cidadã}

O Projeto Educação, Campo e Consciência Cidadã tem como objetivo a alfabetização e escolarização de jovens e adultos e a formação de educadores/ as. Teve origem na atuação de um grupo de professores da Faculdade de Educação da UEMG, que em 1998 elaborou, em parceria com a FETAEMG, MST, FAFIDIA, UFV, Instituto Superior de Ensino e Pesquisa de Ituiutaba (ISEPI) e o Unicentro do Sul de Minas (UNIS), a primeira versão do projeto de alfabetização de jovens e adultos (2000/2001). Essa parceria consolidou-se nos anos posteriores, gerando mais três outras versões do projeto: a segunda versão, realizada no período 2003/2004; a terceira versão, realizada no período 2005/2006, e a quarta versão, realizada no período 2008/2010. Cabe citar que todas essas versões foram financiadas pelo INCRA.

Desenvolvidos em assentamentos e acampamentos das diferentes regiões do estado de Minas Gerais, o Projeto Educação, Campo e Consciência Cidadã, em todas as suas versões, alinha-se à necessidade de a EJA efetivar-se como direito dos povos do campo e como parte das lutas e das conquistas de direitos que têm como protagonistas os movimentos sociais e sindicais. Nesse sentido, ele tem sido um instrumento importante e um espaço significativo de enfrentamento e de afirmação de ações e de políticas educativas que incluam o homem e a mulher do campo na busca de valorização de sua história, sua cultura e de sua cidadania.

A coordenação geral dos projetos, a cargo da UEMG, cumpre o papel de planejar, implementar e acompanhar a gestão política, financeira e pedagógica, definidas em conjunto com representantes de todos os parceiros - MST, FETAEMG, UFV, FAFIDIA, ISEP, UNIS e INCRA - que integram o grupo gestor do projeto. Com reuniões e encontros regulares, o grupo gestor é composto pela coordenação geral, coordenadores regionais (professores e alunos universitários) e coordenadores locais (representantes dos movimentos), além de representantes estaduais do MST, da FETAEMG e do INCRA.

Para a execução das ações do projeto, cada região foi organizada em um coletivo composto por um professor universitário, um aluno universitário e dois coordenadores locais, sendo um representante do MST e outro da FETAEMG. Esse coletivo é responsável pelo planejamento, execução e acompanhamento do projeto nas áreas de realização do trabalho educativo. Cabe a esse grupo mobilizar as comunidades, auxiliá-las na organização das instalações físicas das salas de aula aquisição de lona, lampião, quadro de giz, óculos de grau etc. - e também a busca de parcerias com as prefeituras e outras instituições para fornecimento de diversos equipamentos necessários - 
carteiras, cadeiras, transporte escolar e outras necessidades. Além disso, cabe ao coletivo regional a seleção, capacitação, orientação e acompanhamento aos educadores nos processos pedagógicos, na construção de metodologias compatíveis com os princípios do projeto, entre outras ações. É importante destacar que nesses processos de acompanhamento e orientação não existe uma distinção rígida sobre a quem cabe realizar determinada tarefa ou exercer tal função; de modo geral, todo coletivo participa do planejamento, da execução e avaliação das atividades.

Em termos metodológicos, o processo de formação dos educadores articula e integra diferentes tempos, espaços e atividades formativas, tais como os ciclos estaduais de formação (realizados em âmbito estadual, congregam todos os integrantes do projeto), oficinas regionais (realizadas em âmbito regional, envolvem a participação dos integrantes dos coletivos regionais) e as visitas e acompanhamentos locais (realizadas no âmbito dos assentamentos e acampamentos integrantes do projeto). Na realização de cada versão do projeto, com dois anos de realização, o processo de alfabetização e escolarização de jovens e adultos acampados e assentados da reforma agrária teve uma duração média de oitocentas horas, divididas em dez horas semanais - sendo oito horas dedicadas às atividades presenciais em sala de aula e duas horas destinadas às atividades de planejamento dos/as educadores/as e atividades de formação junto à comunidade. É importante destacar que os/as educadores/as são selecionados pela própria comunidade, em comum acordo com os representantes dos movimentos e das universidades. Além disso, educadores/as e educandos/ as, pelos princípios assumidos pelo projeto, têm autonomia para definirem conjuntamente a dinâmica e a regularidade dos encontros e aulas.

As experiências acumuladas ao longo desses oito anos de existência do Projeto Educação, Campo e Consciência Cidadã têm, portanto, possibilitado aprendizagens, conquistas e desafios que, por sua vez, têm exigido sistematizações e análises que contribuam para orientar os avanços necessários à consolidação da formação de educadores/as e da EJA no contexto da educação do campo. Parte dessas reflexões e análises, especificamente aquelas relacionadas aos desafios e demandas dos processos de formação de educadores/as e educando/as do campo, apresentamos a seguir.

\section{Processos de formação na educação de jovens e adultos no campo}

Analisando os princípios e práticas do Projeto Educação, Campo e Consciência Cidadã em suas quatro versões, um dos aspectos que se destacam é a dinâmica educativa de construção dos processos de formação dos educadores/ as e educandos/as, orientada pelo pressuposto da formação coletiva. Afirmando o Projeto Educação, Campo e Consciência Cidadã como lócus formativo de todos os envolvidos na sua implementação - educadores/as, representantes dos movimentos sociais e sindicais, estudantes e professores/as universitários/as -, a formação realiza-se em diferentes espaços/tempos pedagógicos e em todos os processos de organização do projeto, ou seja, durante o planejamento, organização e implementação dos ciclos estaduais de formação dos educadores/ as, das oficinas regionais e das visitas/ 
acompanhamento às salas de aula nos acampamentos e assentamentos.

Nessa lógica, o planejamento, execução e avaliação das atividades realizam-se por meio de uma dinâmica participativa, envolvendo o grupo gestor do projeto e representantes de todas as parcerias. Busca-se, assim, avançar na elaboração das estratégias de formação, de modo que ampliem a mobilização, aprofundem a discussão acerca dos eixos temáticos e elaborem a programação das atividades em conjunto com todos os integrantes. Nessa perspectiva, os conteúdos dos ciclos e oficinas de formação, assim como as metodologias utilizadas, são construídos e definidos em processos de cogestão entre educadores/as, representantes dos movimentos sociais e sindicais, professores/as e alunos/as universitários/as.

Essa dinâmica educativa, além de favorecer processos intensivos de formação dos educadores/as e a construção coletiva do conhecimento, contribui de maneira significativa para a emergência de um novo olhar para os sujeitos da EJA, seus movimentos de luta, seus modos de vida e as formas de opressão social que vivenciam. Além de inserir essas questões no cotidiano das universidades públicas envolvidas, o Projeto Educação, Campo e Consciência Cidadã tem possibilitado uma maior aproximação e o desenvolvimento de outro olhar para a realidade dos movimentos de luta pela terra e para os seus "sujeitos de direito e sujeitos de deveres do estado", por parte de determinados segmentos universitários.

Aliás, nesse aspecto, é Arroyo (2005) quem nos alerta para a necessidade de a EJA afirmar outro olhar para os seus sujeitos, de maneira que rompa com a concepção preventiva e mora- lizante ainda dominante nas práticas educativas tradicionais destinadas aos jovens e adultos.

Essa mudança de olhar sobre jovens e adultos será uma pré-condição para sairmos de uma lógica que perdura no equacionamento da EJA. Urge ver mais do que alunos ou ex-alunos em trajetórias escolares. Vê-los jovens-adultos em suas trajetórias humanas. Superar a dificuldade de reconhecer que, além de alunos ou jovens evadidos ou excluídos da escola, antes do que portadores de trajetórias escolares truncadas, eles e elas carregam trajetórias perversas de exclusão social, vivenciam trajetórias de negação dos direitos mais básicos da vida, ao afeto, à alimentação, à moradia, ao trabalho e à sobrevivência. (idem, p. 24)

Portanto, para o autor é fundamental mudar a representação sobre esses sujeitos, enxergando-os como sujeitos de direito e sujeitos de deveres do Estado. Esse avanço exige, entretanto, clareza para que se abandonem orientações supletivas e assistencialistas, de maneira que contribuam para que a EJA se efetive como uma política pública, como um dever do Estado.

Por ocasião do III Seminário Nacional do PRONERA, momento de comemoração dos dez anos de sua existência, muito foi discutido no intuito de salientar a importância da garantia do direito aos homens e mulheres do campo à educação. Molina (2008), na oportunidade, analisando a prática educativa que vem sendo promovida para se mostrar a legitimidade e a legalidade de ações que efetivem esses direitos, 
reforça o princípio de que a educação, em um Estado Democrático de Direito como o que vivemos, é um direito social e deve ser materializada com políticas públicas que garantam a educação dos povos do campo.

Assim, é necessário e urgente que as distorções e desigualdades históricas, construídas no acesso dos sujeitos do campo à educação, sejam reparadas e que se considere a especificidade das condições sociais, culturais e econômicas sob as quais eles vivem e produzem significados para o mundo. Essa população, portanto, demanda políticas públicas específicas. É nesse sentido que as ações do PRONERA e, mais especificamente, do Projeto Educação, Campo e Consciência Cidadã se fazem necessárias para que a população do campo tenha condições de acessar o direito à educação. Dessa forma,

Conceber essas políticas impõe-nos desafios da produção de novos saberes inter-transdisciplinares, que sejam capazes de articular diferentes dimensões da vida dos sujeitos do campo, aliadas ao seu processo educacional, ou seja, uma escola colada ao chão da vida, ligada aos processos de produção da existência social desses sujeitos. (idem, p. 30)

Esse reconhecimento da necessidade de uma educação "colada ao chão da vida", como orientação dos processos de formação dos educadores/ as, possibilita reflexões e debates que incorporem essas dimensões do direito, favorecendo melhor compreensão e clareza dos educadores/as sobre a dimensão política e de luta da EJA e da educação do campo. Nesse aspecto, as experiências do Projeto Educação,
Campo e Consciência Cidadã indicam que a simples presença da sala de aula nos espaços de vida dos educandos/as, ou seja, nos assentamentos e acampamentos da reforma agrária, além de garantir o acesso e a realização dos processos educativos, materializa uma perspectiva de vida centrada na luta, na mobilização e na organização em prol de uma sociedade melhor, favorecendo, assim, o reconhecimento e a afirmação da identidade dos sujeitos assentados e acampados, bem como o fortalecimento das forças sociais ali existentes.

Contribui, ainda, na realização desse princípio de vinculação da formação à realidade de vida dos sujeitos, na perspectiva teórica orientadora dos processos de formação dos educadores/as. Assim, tendo como eixo de construção dos processos formativos a especificidade do trabalho educativo, assumimos os princípios e concepções de Paulo Freire, para quem aprender a ler e escrever é uma atividade que não se dá descolada da vida e dos problemas nela enfrentados, pois "nenhuma ação educativa pode prescindir de uma reflexão sobre o homem e de uma análise sobre suas condições culturais" (Freire, 1981, p. 61). Assumir que a sala de aula não está separada da vida pressupõe o desenvolvimento de um trabalho educativo que busca adequar-se à realidade do campo, ao mesmo tempo em que possibilita a construção de novos significados da cultura no processo de intervenção na realidade, permitindo que os sujeitos ali inseridos (educandos/as e educadores/as) procedam à elaboração de uma crítica do mundo em que vivem.

Nessa perspectiva, o trabalho educativo de alfabetização/escolarização é concebido como um fenômeno comple- 
xo que, ultrapassando as habilidades de codificação/decodificação de signos/ símbolos, se configura como um fator fundamental para a busca da emancipação política e autônoma dos assentados e acampados da reforma agrária. A alfabetização/escolarização, nessa lógica, é trabalhada de forma que proporcione aos educandos/as se aperfeiçoarem como observadores conscientes de sua realidade, em condições de ad-mirar, "olhar de fora", para refletir sobre essa realidade e transformá-la.

A formação dos educadores/as e a alfabetização/escolarização de jovens e adultos realizadas no âmbito do Projeto Educação, Campo e Consciência Cidadã são processos que, de maneira articulada, afirmam a dimensão política da educação, por meio de práticas educativas emancipatórias que priorizam a relação intrínseca entre educação e cultura, orientadas por temas como organização política, movimentos sindicais e sociais, saúde, trabalho, ecologia, agricultura, produção e cultura. Nessa dinâmica educativa, a educação realiza-se nos diferentes espaços e em diferentes tempos pedagógicos, buscando afirmar uma formação humana construída coletivamente e orientada pelos princípios de autonomia e emancipação dos diferentes sujeitos da EJA.

\section{Os sujeitos da EJA}

Associadas às reflexões mais diretamente relacionadas à formação dos educadores/as e educandos/as no contexto do Projeto Educação, Campo e Consciência Cidadã, emergem questões também importantes para a compreensão da EJA e da formação de educadores/as do campo. São elas: quem são os sujeitos da educação de jovens e adultos? Especificamente: quem são os educadores/as? Quem são os educandos/as? A compreensão sobre os sujeitos da EJA ainda é uma lacuna existente nas produções teóricas da área. Conforme destaca Arroyo (2005), as poucas informações e conhecimentos disponíveis na literatura da área encontram-se mais relacionadas à realidade da EJA em contexto urbano, sobretudo em uma relação direta com o trabalho na indústria e com outros setores relacionados.

Segundo o autor, a EJA em nossa sociedade ainda é um campo não consolidado de pesquisas, investigações, políticas públicas, diretrizes educacionais, formação de educadores e intervenções pedagógicas. Ele considera, ainda, como características marcantes da EJA, na atualidade educacional, a necessidade de o Estado assumir a responsabilidade para com a construção de políticas públicas, com a formação de educadores, produção teórica e intervenções pedagógicas, assim como a busca da configuração de sua especificidade. E, nesse aspecto, Arroyo (2005) ressalta que um dos elementos fundamentais para essa configuração da especificidade da EJA é a compreensão sobre os sujeitos que dela participam.

Torna-se, portanto, de fundamental importância ampliar os olhares sobre os sujeitos da EJA, de maneira que considerem não apenas suas trajetórias escolares truncadas, mas que construam uma sensibilidade para essas trajetórias de vida, para a sua identidade coletiva de classe, gênero, raça, etnia. É preciso enxergar, em cada uma das trajetórias, a história perversa de exclusão social, de negação de direitos básicos à vida, ao trabalho e a sobrevivência a que foram submetidos. Daí a necessidade, desta- 
cada por Arroyo (2005), de captar as trajetórias humanas na sua totalidade e percebê-las como construtoras de percursos de socialização e sociabilidade, de busca de saberes, de interrogações, de tentativas de escolhas e de formação de valores. As trajetórias escolares e humanas truncadas não significam, assim, a paralisação nos processos de formação mental, ética, identitária, cultural, social e política, na medida em que jovens e adultos (homens e mulheres) trazem consigo um acúmulo de formação, de aprendizagens e de saberes.

Analisando a educação de jovens e adultos trabalhadores em nossa sociedade, Rummert (2007) considera esse público como possuidor de "marcas de longa duração", que foram sedimentadas ao longo de séculos de dominação no Brasil: "estigma das relações escravocratas"; autoritarismo (tutela em relação aos trabalhadores); modernização pelo alto; práticas populistas; entre outras. Soma-se a isso, segundo a autora, a negação das condições de acesso e, mais recentemente, de permanência na escola à maioria da classe trabalhadora. É claro que a história de luta desses jovens e adultos trabalhadores pela reforma agrária vem buscando romper essas "marcas de longa duração". Todavia, apesar de ser um processo que se intensificou a partir dos anos de 1980, as mudanças na forma de pensar, conhecer a si mesmo e ler o mundo dentro de uma perspectiva diferente daquelas deixadas pelas marcas de exclusão e da dominação não se realizam de modo automático.

É nessa direção que podemos situar também os resultados do Programa de Estudos "Educação de jovens e adultos em áreas de reforma agrária em Minas Gerais: os processos educativos gestados no Projeto Educação, Campo e Consciência Cidadã”, especificamente do subprojeto de pesquisa Representações sociais e trajetórias de educandos do PRONERA (Silva, 2009), que revelam um conjunto de representações, vivências e sentimentos que, direta ou indiretamente, influenciaram e deixaram marcas significativas nas trajetórias dos/as educandos/as entrevistados/as, sobretudo em relação ao processo de escolarização formal. É sempre na perspectiva da negação do direito à escola que as experiências educacionais são representadas.

Nessas representações destacam-se as dificuldades vivenciadas no acesso e na permanência escolar, a falta de compreensão das famílias sobre a importância da educação formal, as dificuldades de aprendizagem e das relações professor/aluno, entre outras. Enfim, são vivências que sustentam trajetórias escolares marcadas pela violência, pela exclusão social e pelo "ressentimento escolar". Entretanto, também são essas marcas que, na atualidade, colaboram para uma valorização da experiência de educação de jovens e adultos que tem sido vivenciada no âmbito do Projeto Educação, Campo e Consciência Cidadã.

Assim, nossas análises também evidenciam, conforme perspectiva ressaltada por Rummert (2007), as dificuldades dos/as educandos/as da EJA em alterar as representações e os significados deixados pelas marcas de exclusão e dominação. Nesse processo, é imprescindível a superação de velhas representações que associam as frustrações em suas trajetórias escolares às características individuais, de maneira que não reproduzam uma tendência que, segundo a autora, é muito comum entre os jovens e adultos trabalhadores: 
culpam a si mesmos pelo fracasso na escola e acreditam que, por isso, é natural que ocupem na sociedade patamares mais precários de existência.

$[\ldots]$ no que tange às suas visões sobre educação em geral, e sobre aquela a que tiveram acesso, os trabalhadores entrevistados, além de valorizarem a frequência à escola, tenderam a emitir opiniões negativas sobre si mesmos, ou as de seus familiares sobre eles, ou deles sobre membros de suas famílias, quando se defrontraram com experiências de repetência, evasão ou abandono prematuro da escola, ainda que muitos tenham feito referências gerais a dificuldades de ordem econômica que os remeteram à inserção precoce na PEA. No entanto, ainda que tenham sido mencionadas essas últimas referências, as quais apontam para determinações sociais e não individuais dos fracassos/limitações/exclusões escolares, elas não são aparentemente entendidas por eles como históricas, mas como fatalidades. Daí, talvez, o processo de autoculpabilização. (Ferretti et al., 2002 apud Rummert, 2007, p. 20)

E, nesse aspecto, cabe destacar que os princípios e práticas orientadores dos processos de formação de educadores/as e educandos/as do Projeto Educação, Campo e Consciência Cidadã têm contribuído, conforme resultados de nossas investigações, tanto para a superação de muitas dessas representações e marcas de longa duração, quanto para possibilitar o conhecimento e a desmistificação dos educadores/as e educandos/as como sujeitos da EJA. Assim, também em relação aos edu- cadores/as, os resultados do Programa de Estudo revelam um conjunto das aprendizagens por eles/as desenvolvidas nos diferentes tempos e espaços pedagógicos do projeto, do movimento social, assim como de outros espaços e/ ou processos de escolarização formal. Especificamente, no subprojeto de pesquisa Representações de mulheres educadoras sobre a escrita (Rosa; Costa, 2009), no qual buscamos investigar as representações de mulheres sobre a escrita, nossas análises indicam, entre outros aspectos, que a formação das educadoras se encontra ancorada nas experiências por elas vivenciadas tanto no interior dos movimentos sociais, quanto nas ações do projeto de educação de jovens e adultos.

Buscando aprofundar a compreensão sobre essas representações das educadoras, tornou-se necessário avançar em direção a uma melhor compreensão sobre a identidade desses sujeitos da EJA, valendo-se das seguintes questões: quem são as mulheres que participam do Projeto Educação, Campo e Consciência Cidadã? Como elas chegaram aos movimentos sociais ou sindicais dos quais participam? Como constroem sua identidade e práticas como educadoras? Como se identificam como mulheres a partir das suas trajetórias nos movimentos e suas aprendizagens nos assentamentos e acampamentos?

As análises realizadas com as educadoras revelaram que essas mulheres-educadoras se veem envolvidas com o seu processo de formação e se mostram atentas ao lugar que ocupam nos movimentos. Com idades variando de 19 a 41 anos, elas têm assumido espaços de lideranças tanto no movimento de luta pela terra, quanto nas atividades de 
organização social dos acampamentos ou assentamentos de reforma agrária. Atentas aos seus processos de escolarização, reconhecem a necessidade de continuidade dos estudos e da formação e, para tal, empreendem ações na realização desses propósitos. Todavia, não deixam de reconhecer a existência de outros espaços significativos de aprendizagens, para além de processos de educação formal. Nesse aspecto, apesar de identificarem a participação que têm no Projeto Educação, Campo e Consciência Cidadã como uma atuação em espaço não formal, reconhecem-no como um espaço sistematizado de ampliação e construção de conhecimentos, assim como de valorização e de afirmação da identidade de educadora.

Identificamos, ainda, que em suas trajetórias de vida as educadoras refletem, sistematicamente, sobre suas histórias, suas condições de vida, suas escolhas e sobre os lugares que ocupam como mulheres. Assim, retomando Arroyo (2005), as análises de suas trajetórias escolares e humanas, ao contrário de uma paralisação nos processos de formação mental, ética, identitária, cultural, social e política, evidenciam que essas mulheres trazem consigo um acúmulo de formação e de aprendizagens, construídas ao longo de suas vivências e experiências nos movimentos. As análises oriundas dos estudos sobre gênero têm nos revelado quanto as relações entre homens e mulheres são marcadas, em nossa sociedade, por uma assimetria entre os direitos e as condições de vida nas quais esses sujeitos estão inseridos, com base nas relações de poder em uma sociedade que ainda valoriza o masculino e discrimina o feminino. Cabe ainda registrar que as questões de gênero têm sido um tema que vem ganhando destaque entre as pesquisas realizadas sobre a educação popular, bem como nos discursos produzidos pelas lideranças dos movimentos sociais e nos materiais de estudo produzidos por estes (Norback et al., 2008, p. 178).

No meio rural brasileiro, as condições de vida das mulheres não são diferentes. Assim, ainda na atualidade, a posição da mulher na organização dos acampamentos e assentamentos, na transmissão do patrimônio familiar e na militância passa pelo lugar do feminino e do masculino, construídos historicamente. Pesquisas realizadas em diferentes regiões do Brasil (Carneiro, 2001) mostram que, apesar das diferenças socioculturais e das condições das famílias pesquisadas, o lugar ocupado pelas mulheres no processo produtivo agrícola é sempre percebido como secundário, tanto pelos homens como pelas próprias mulheres. As relações marido/mulher enfatizam a hierarquia, autoridade e dominação masculina sobre a mulher.

Todavia, segundo Schwendler (2002), na luta pela conquista da terra, a mulher torna-se um agente histórico fundamental, quer seja pelo enfrentamento da situação dada pela ocupação, quer seja pelas relações que constrói pela sua presença ativa na luta. A presença feminina torna-se fundamental na luta pela terra e a torna possível. O ser mulher é compreendido como uma categoria cultural e histórica perpassada pelas relações sociais, ou seja, uma construção social com base nas relações estabelecidas entre mulheres e homens, nos significados atribuídos ao feminino e ao masculino na família, no trabalho, nas lutas sociais e na dinâmica do assentamento. Os espaços reservados e os papéis atribuídos ao 
masculino e ao feminino redefinem-se durante o processo de ocupação da terra e de formação do acampamento, pela própria organicidade produzida na formação de comissões, em que as tarefas são divididas e assumidas por mulheres e homens.

Entretanto, apesar das relações de poder assimétricas ainda presentes no cotidiano de vida das educadoras, nossas análises revelam a existência de um esforço significativo por parte delas em evidenciar essas relações, de maneira que garantam alternativas mínimas para que estas sejam alteradas, no intuito de ampliar e/ou construir relações sociais mais solidárias, coletivas e igualitárias.

\section{Desafios e demandas da formação dos sujeitos da EJA}

As análises e reflexões em torno das ações educativas e práticas pedagógicas do Projeto Educação, Campo e Consciência Cidadã, ao mesmo tempo em que possibilitam ampliar nossos olhares sobre os sujeitos da EJA e sobre os processos educativos, aprendizagens, representações e trajetórias desses sujeitos, revelam também contradições, desafios e demandas diversas que marcam os processos formativos de educadores/as e educandos/as de EJA, construídos na interface da educação do campo. Entre esses desafios, destacamos aqueles enfrentados pelos/ as educadores/as e educandos/as na dinâmica social e política de suas vidas e que, ao explicitarem tensões e fronteiras da educação formal com a educação não formal, indicam demandas para os processos formativos da EJA em áreas de reforma agrária.
Nessa perspectiva, um dos primeiros aspectos a ser destacado é a consideração de que os assentamentos e acampamentos ${ }^{3}$ de reforma agrária se configuram como espaços e organizações sociais diferenciadas, nos quais as especificidades se expressam nos desafios enfrentados pela EJA. Assim, a constituição dos grupos de educandos/ as de EJA, os enfrentamentos vivenciados por eles coletivamente, assim como a materialidade da sala de aula, têm se mostrado como espaços e processos importantes na sustentação do direito desses sujeitos de inserção e presença nos processos de alfabetização e escolarização construídos cotidianamente no espaço da sala de aula. Todavia, para tanto, os/as educandos/as vivenciam dificuldades e limitações de várias ordens: as exigências próprias do mundo do trabalho; as atividades produtivas intensificadas no período de colheita ou plantio; as distâncias de suas moradias; as dificuldades de locomoção, oriundas da idade avançada, da falta de meios de transportes e/ou da precariedade de condições das estradas principalmente nos períodos de chuva.

\footnotetext{
O movimento social ocupa a terra devoluta ou improdutiva e ali as pessoas passam a viver em um acampamento que tem um sentido pedagógico de organização da vida em comum das famílias sem-terra debaixo das lonas, em situação de extrema precariedade material, mas de muita riqueza humana. É um espaço social de formação identitária de uma coletividade. Quando as terras são conquistadas pelo movimento social e, na perspectiva do Estado, a área é destinada a um conjunto de famílias sem-terra como forma de solucionar um problema fundiário, constitui-se um assentamento. Para o MST, o assentamento é um processo histórico de transição e transformação, de organização do território, do espaço agrário em questão (Caldart, 2004).
} 
Acrescentem-se, ainda, situações nas quais os/as educandos/as vivenciam processos de despejo; de transformação do acampamento em assentamento; de adaptação à nova moradia que, às vezes, diferente da organização por agrovilas fica mais distante das outras casas e dos espaços de convivência comunitária, dificultando a presença em sala de aula, entre outras.

Assim, a presença de diferentes organizações sociais, com diferentes demandas, revelando um conjunto de desafios enfrentados pelos/as educando/as na dinâmica social e política de suas vidas, explicitam as tensões e fronteiras da educação formal com a educação não formal próprias da EJA, apresentando desafios de várias ordens para a formação de educadores/as da EJA em áreas de reforma agrária. Assim, momentos que antecedem a uma ordem de despejo, momentos de divisão dos lotes, de construção das moradias, momentos de colheita são momentos nos quais a dinâmica educativa da sala de aula tem seus ritmos alterados, seja com a paralisação das aulas, seja pela condição de alguns educandos/as que ficam infrequentes. São momentos que exigem dos educadores/as e de todos os envolvidos o exercício do diálogo para definições e deliberações coletivas sobre estratégias possíveis quer seja na perspectiva de alteração dos horários, dias e conteúdos das aulas, quer seja na redefinição de práticas, espaços e tempos alternativos para vivências do processo ensino-aprendizagem.

Nesse aspecto, as práticas e reflexões construídas no âmbito da educação popular, também presentes no campo da educação não formal de jovens e adultos, apresentam contribuições e questões importantes para a construção de alternativas pelos educadores/as e educandos/as, conforme revelam os trabalhos de Brandão (2002), Freire (1989), Paiva (1987), Paludo (2007), entre outros. Dessa maneira, podemos refletir: Que momentos podem ser considerados aula? Que abertura é construída pelos educandos/as para inclusão dos/as colegas que retornam após um período de afastamento? Nessa perspectiva, a própria definição do que seja considerado uma aula passa pela discussão e (re) definição, realizadas em conjunto por educandos/as e educadores/as, sobre as aprendizagens envolvidas e os espaços de formação existentes no cotidiano de vida e de trabalho dos sujeitos da EJA.

Nessa lógica, os momentos de uma reunião, de uma assembleia, entre outras atividades próprias do cotidiano dos assentamentos e acampamentos, tornam-se momentos importantes de "aulas". Todavia, é importante destacar que nossas reflexões em torno das aprendizagens de jovens e adultos indicam que muitas delas necessitam de sistematização, frequência e continuidade para que sejam construídas pelos/ as educandos/as, de maneira que eles/as produzam sentido para essas aprendizagens. Uma dessas reflexões diz respeito ao processo de alfabetização entendido como um processo de apropriação do sistema alfabético em uma dinâmica de construção de sentidos para os/ as educandos/as (Albuquerque; Leal, 2004). Assim, a apropriação do sistema alfabético exige momentos sistemáticos de observação, de análise, de comparação da língua(gem) oral e escrita, momentos que podem ser considerados mais formais.

É importante ressaltar, entretanto, que a sala de aula no Projeto 
Educação, Campo e Consciência Cidadã ainda assume uma centralidade na dinâmica de formação, sendo o lócus privilegiado de realização dos processos de alfabetização e escolarização dos/as educandos/as. Essa centralidade pode ser compreendida pelo fato de que, no contexto dos sujeitos do campo, mais que espaço formal de aprendizagens, a sala de aula assume um significado de conquista de direito pelos assentados/ as e acampados/as da reforma agrária, simbolizando a certeza de que por meio da organização e da luta se torna possível efetivar os direitos.

Acrescente-se, ainda, que geralmente são as comunidades que se mobilizam para construir e/ou adequar o espaço físico da sala de aula, fazendo escolhas sobre as possibilidades de sua utilização naquela realidade. Em muitos assentamentos e/ou acampamentos, a presença da sala de aula favorece um novo vigor nessas realidades, estimulando os moradores a trocarem experiências, dialogarem sobre a vida, os problemas da localidade, do município etc. São esses processos educativos que colaboram para que a sala de aula, no cotidiano das ações do Projeto Educação, Campo e Consciência Cidadã, ultrapasse as fronteiras do espaço físico a ela destinado.

Todavia, a despeito da centralidade da sala de aula como lócus de formação tanto na EJA quanto na educação formal, os diferentes espaços/tempos pedagógicos vivenciados pelos educandos/as e educadores/as no projeto têm favorecido uma compreensão das possibilidades existentes em outros ambientes e espaços, que não os convencionais, como espaços/tempos educativos potenciais na educação de jovens e adultos.
Finalizando, gostaríamos de ressaltar os desafios dos processos de formação de educadores/as e educandos/ as no Projeto Educação, Campo e Consciência Cidadã, mais especificamente aqueles que se colocam na interface de suas ações na educação de jovens e adultos com a educação do campo. O primeiro deles refere-se à educação de jovens e adultos se efetivar como direito dos povos do campo e como parte das lutas e das conquistas de direitos que têm como protagonistas os movimentos sociais e sindicais. E, nesse aspecto, consideramos que a EJA constitui um instrumento importante e um espaço significativo de enfrentamento e de afirmação de ações e de políticas educativas que incluam o homem e a mulher do campo na busca de valorização de sua história, cultura e cidadania. Associado a essa dimensão, outro desafio é a problematização da dimensão política da educação, por meio de práticas educativas emancipatórias, capazes de priorizar a relação intrínseca entre educação e cultura. Nosso entendimento é que a construção de uma educação de jovens e adultos exige um diálogo efetivo com a educação do campo, compartilhando reflexões e práxis. Esse movimento favorece deslocar o olhar de uma educação de jovens e adultos urbanizada para outra direção: a de constituição e construção de uma perspectiva de EJA do campo. Nesta perspectiva, outro desafio é a necessidade de avançarmos em pesquisas e produções acadêmicas que busquem maior articulação entre esses dois campos, contribuindo para a construção de um diálogo mais consistente entre eles e, sobretudo, assumindo essa dimensão de interface educação de jovens e adultos/educação do campo. Esse é um dos desafios atuais. 


\section{Referências bibliográficas}

ALBUQUERQUE, Eliana Borges C.; LEAL, Telma Ferraz (Orgs.). A alfabetização de jovens e adultos em uma perspectiva de letramento. Belo Horizonte: Autêntica, 2004.

ANDRADE, Márcia Regina et al. A educação na reforma agrária em perspectiva: uma avaliação do Programa Nacional de Educação na Reforma Agrária. São Paulo: Ação Educativa/ Brasília: PRONERA, 2004.

ARROYO, Miguel. Educação de jovens e adultos: um campo de direitos e de responsabilidade pública. In: SOARES, Leôncio; GIOVANETTI, Maria Amélia; GOMES, Nilma Lino (Orgs.). Diálogos na educação de jovens e adultos. Belo Horizonte: Autêntica, 2005.

BARDIN, Laurence. L'analyse de contenu. Paris: PUF, 1977.

BOURDIEU, Pierre. Esboço de uma teoria da prática. In: ORTIZ, R. Pierre Bourdieu. 2. ed. São Paulo: Ática, 1994.

BRANDÃO, Carlos Rodrigues. A educação popular na escola cidadã. Rio de Janeiro: Vozes, 2002.

CALDART, Roseli. Pedagogia do Movimento Sem Terra. Petrópolis: Vozes, 2004.

CARNEIRO, Maria José. Herança e gênero entre agricultores familiares. Revista de Estudos Femininos, v. 9, n. 1, p. 22-55, 2001.

COSTA, Vânia Aparecida; ROSA, Walquíria Miranda. Trajetórias e representações de escrita de educadoras de EJA. In: ENCONTRO NACIONAL DE DIDÁTICA E PRÁTICA DE ENSINO, 15., Belo Horizonte, 2010. Anais... Belo Horizonte, ENDIPE, 2010.

FREIRE, Paulo. Educação e mudança. Rio de Janeiro: Paz e Terra, 1981.

. Quefazer: teoria e prática em educação popular. Rio de Janeiro: Vozes, 1989.

MOLINA, Mônica Castagna. A constitucionalidade e a justiciabilidade do direito à educação dos povos do campo. In: SANTOS,
Clarice Aparecida (Org.). Por uma educação do campo. Campo, Políticas Públicas - Educação. Brasília: INGRA; MDA, 2008.

MOSCOVICI, Serge. A representação social da psicanálise. Rio de Janeiro: Zahar, 1978.

NORBACK, Altair et al. A questão de gênero em espaços educativos dos movimentos sociais do campo. In: MACHADO, Carmem Lúcia Bezerra; CAMPOS, Christiane Senhorinha Soares; PALUDO Conceição (Orgs.). Teoria e prática da educação do campo: análise de experiências. Brasília: MDA, 2008.

OLIVEIRA, César; SANTOS, Clarice Aparecida. Educação na perspectiva de um novo modelo de desenvolvimento na reforma agrária. In: SANTOS, Clarice Aparecida (Org.). Por uma educação do campo. Campo, Políticas Públicas - Educação. Brasília: INCRA;MDA, 2008. p. 15-18.

PAIVA, Vanilda Pereira. Educação popular e educação de adultos. 4. ed. São Paulo: Loyola, 1987.

PALUDO, Conceição. Da raiz herança da educação popular à pedagogia do movimento e a educação do e no campo: um olhar para a trajetória de educação do MST. In: REUNIÃO ANUAL DA ANPED, 30., Caxambu, 2007. Anais... Caxambu, ANPED, 2007.

RIBEIRO, Vera Maria Massagão (Org.). Educação de jovens e adultos: novos leitores novas leituras. Campinas: Mercado de Letras; Associação de Leitura do Brasil - ALB/ São Paulo: Ação Educativa, 2001.

ROSA, Walquíria Miranda; COSTA, Vânia Aparecida. Educação de jovens e adultos em áreas de reforma agrária em Minas Gerais: representações de mulheres/educadoras sobre a escrita. Buenos Aires: IX RAM, 2009.

RUMMERT, Sonia Maria. A "marca social” da educação de jovens e adultos trabalhadores. In: SIMPÓSIO TRABALHO E EDUCAÇÃO, 4., 2007, Belo Horizonte, NETE/FAE/ UFMG, v. 1, n. 4, ago. 2007. 
SCHWENDLER, Sônia Fátima. A construção do feminino na luta pela terra e na recriação social do assentamento. Vozes Sem Terra: as imagens e as vozes da despossessão - estudos, depoimentos \& referências. Disponível em: <http://www.landless-voices. org/vieira/shared/ev.css 2002>.

SILVA, Lourdes Helena. Educação do campo e pedagogia da alternância. Sísifo - Revista de Ciências da Educação, Lisboa, v. 5, p. 105112, 2008.

Projeto Educação, Campo e Consciência Cidadã: representações sociais e trajetórias de educandos do PRONERA. In: REUNIÃO ANUAL DA ANPED, 32., Caxambu, 2009. Anais... Caxambu, ANPEd, 2009.

THIOLLENT, Michel. Metodologia da pesquisa ação. São Paulo: Cortez, 1986.

LOURDES HELENA DA SILVA, doutora em educação pela Pontifícia Universidade Católica de São Paulo (PUG-SP), com pós-doutorado em ciências de educação pela Universidade de Lisboa (UL), é professora do Programa de Pós-Graduação em Educação da Universidade Federal de Viçosa (UFV) e bolsista produtividade do CNPq. Publicações mais importantes: As experiências de formação de jovens do campo: alternância ou alternâncias? (Viçosa: Editora UFV, 2003); Cenários da educação no meio rural de Minas Gerais (Curitiba: CRV, 2009); Projeto Educação, Campo e Consciência Gidadã: representações sociais e trajetórias de educandos do PRONERA (Anais... REUNIÃO ANUAL DA ANPED, 32., 2009); Concepções, práticas e dilemas das escolas do campo: a alternância pedagógica em foco (In: DALBEN, Angela; DINIZ, Júlio; SANTOS, Lucíola (Orgs.). Convergências e tensões no campo da formaçã̃o e do trabalho docente. Belo
Horizonte: Autêntica, 2010. p. 425-440); Quem são as mulheres alfabetizadoras?, em coautoria com COSTA, Vânia Aparecida; ROSA, Walquíria Miranda (Anais... III ENGONTRO NAGIONAL DE PESQUISA EM EDUCAÇÃO DO CAMPO, 2010). Atua na área de Educação do Campo, Educação de Jovens e Adultos e Pedagogia da Alternância. Pesquisas em andamento: "Novas faces da pedagogia da alternância na educação do campo", com financiamento do CNPq e da FAPEMIG; "Práticas de educação de jovens e adultos, letramento e alternâncias", com financiamento do Observatório da Educação/CAPES. E-mail:1hsilva@ufv.br

VÂNIA APARECIDA COSTA, doutora em educação pela Universidade Federal de Minas Gerais (UFMG), é professora da Faculdade de Educação da Universidade do Estado de Minas Gerais (UEMG), pesquisadora do Núcleo de Estudos e Pesquisas em Educação de Jovens e Adultos (NEPEJA/FAE/UEMG). Publicações mais importantes: Letramento em escolas do campo, coautoria com MARINHO, M. e RIBEIRO, M. (In: GRACINDO, Regina V. et al. (Orgs.). Educação como exercício de diversidade: estudos em campos de desigualdades sócio-educacionais. 1. ed. Brasília: Liber Livro, 2007); Práticas de leitura em uma sala de aula da Escola do Assentamento: o local e o global nas práticas de leitura (Anais... III GOLÓQUIO INTERNACIONAL DE LETRAMENTO E GULTURA ESGRITA, 2010); Trajetórias e representações de escrita de educadoras de EJA, em coautoria com ROSA, Walquíria Miranda (Anais... XV ENDIPE, 2010); Quem são as mulheres alfabetizadoras?, em coautoria com ROSA, Walquíria Miranda; 
SILVA, Lourdes Helena (Anais... III ENCONTRO NACIONAL DE PESQUISA EM EDUCAÇÃO DO CAMPO, 2010); Leitura em uma sala de aula de assentamento de reforma agrária (Anais... VIII REUNIÓN DE ANTROPOLOGIA DEL MERCOSUR, 2009). Atua na área da Educação do Campo, Educação de Jovens e Adultos e Linguagem/Práticas de Leitura. Pesquisas em andamento: "Concepções de letramento de sujeitos em diferentes processos de escolarização em um assentamento de reforma agrária", com financiamento da FAPEMIG; "Práticas de educação de jovens e adultos, letramento e alternâncias", com financiamento do Observatório da Educação/CAPES.

E-mail:vânia.costa63@gmail.com

WALQUÍRIA MIRANDA ROSA, mestre em educação pela Universidade Federal de Minas Gerais (UFMG) e doutoranda em educação do Programa de Pós-Graduação em Educação da Faculdade de Educação também na UFMG. É professora da Faculdade de Educação da Universidade do Estado de Minas Gerais (UEMG), pesquisadora do Núcleo de Estudos e Pesquisas em Educação de Jovens e Adultos (NEPEJA/FAE/UEMG) e integrante da equipe do Observatório da Educação do Campo. Publicações mais importantes: Culture politique, scolarisation et pratiques d appropriation: la méthode mutuelle dans le Minas Gerais (Brésil) au XIXe Siècle, em coautoria com FARIA FILHO, Luciano Mendes; INÁCIO, Marcilaine Soares (Paedagogica historica, Belgica, v. 41, n. 6, 2005); Educação de jovens e adultos em áreas de reforma agrária em Minas Gerais: representações de mulheres/ educadoras sobre a escrita, em coautoria com Vânia Aparecida Costa (Anais... VIII REUNIÓN DE ANTROPOLOGIA DEL MERCOSUR, 2009); Trajetórias e representações de escrita de educadoras de EJA, em coautoria com COSTA, Vânia Aparecida (Anais... XV ENDIPE, 2010); Quem são as mulheres alfabetizadoras?, em coautoria com COSTA, Vânia Aparecida; SILVA, Lourdes Helena (Anais... III ENCONTRO NACIONAL DE PESQUISA EM EDUCAÇÃO DO CAMPO, 2010). Atua na área de Educação de Jovens e Adultos, Educação do Campo e História da Educação. Pesquisa em andamento: "Práticas de educação de jovens e adultos, letramento e alternâncias", com financiamento do Observatório da Educação.

E-mail:wmrosa2032@yahoo.com.br

Recebido em outubro de 2010 Aprovado em outubro de 2010 


\section{A educação de jovens e adultos em áreas de reforma agrária:}

\section{desafios da formação de educadores do campo}

Este artigo apresenta análises e reflexões construídas com base nos resultados do Programa de Estudos Educação de Jovens e Adultos em Áreas de Reforma Agrária em Minas Gerais: os processos educativos gestados no Projeto "Educação, Campo e Consciência Cidadã", de maneira que evidencie conquistas, demandas e desafios enfrentados pelos sujeitos da EJA nos processos formativos vivenciados. As análises, ao mesmo tempo em que possibilitam ampliar os olhares sobre esses sujeitos, suas representações, trajetórias, seus processos educativos e aprendizagens, revelam diversas contradições, desafios e demandas que marcam os processos formativos dos educadores de jovens e adultos construídos na interface da Educação do Campo. Dentre eles, destacam-se os desafios enfrentados por eles na dinâmica social e política de suas vidas e que, ao explicitarem tensões e fronteiras da educação formal com a educação não formal, indicam demandas para os processos formativos da EJA em áreas de Reforma Agrária.

Palavras-chave: Educação de Jovens e Adultos; formação de educadores de EJA; Projeto "Educação, Campo e Consciência Cidadã" 


\section{The youth and adult education in land reform areas: chalenges of the training of rural areas' educators}

This paper aims to present analysis and systematizations based on the results of the Adult Education program in the Land Reform areas situated in the State of Minas Gerais: the educational process constructed by the "Education, Rural and Citizenship Awareness Project", in order to highlight the achievements, necessities and challenges faced by Youth and Adult Education educators in the formative process. The analyses at the same time enable to expand the importance given to the subjects attended by the Adult Education Program, their trajectories e learning processes, also reveal several contradictions, challenges and demands which mark the EJA educator and learners training process constructed on the interface of rural education. Among these, stands out the challenges faced by the educators and the learners in the social dynamic and their political lives, which explicit tensions and barrier in the formal and informal education, and also indicate demands for EJA training process in the land reform areas.

Key words: Youth and Adult Education; training of Youth and Adult educators; "Education, Field and Citizen Awareness" Project.

\section{La educación de jóvenes y adultos en áreas de reforma agraria: desafíos da la formación de educadores del campo}

Este artículo presenta análisis y reflexiones construidas a partir de los resultados del Programa de Estudios de Educación de Jóvenes y Adultos en Áreas de Reforma Agraria en Minas Gerais: los procesos de educación desarrollados en el "Proyecto de Educación, Campo y Conciencia ciudadana", de manera a evidenciar conquistas, demandas y desafíos enfrentados por los sujetos de EJA en los procesos formados por las vivencias. Los análisis, al mismo tiempo en que dan la posibilidad de ampliar la visión sobre estos sujetos, sus representaciones, trayectorias, procesos educativos y de aprendizaje, revelan varias contradicciones, desafios y solicitudes que marcan los procesos de formación de los educadores de jóvenes y adultos construidos en la interfaz de la Educación del Campo. Entre ellos, se destacan los desafios enfrentados por ellos en la dinámica social y política de sus vidas y que al expresar tensiones y fronteras de la educación formal con la educación no formal, indican demandas para los procesos de formación de EJA en las áreas de reforma agraria.

Palabras claves: Educación de jóvenes y adultos; formación de educadores de EJA; "Proyecto Educación, Campo y Conciencia Ciudadana" 